\title{
VICISSITUDES E TRIUNFOS DO HABEAS CORPUS COLETIVO 143.641/SP: PROTAGONISMOS E ATIVISMO JUDICIAL?
}

\author{
Maiquel Ângelo Dezordi Wermuth* \\ Laura Mallmann Marcht**
}

SUMÁRIO: Considerações iniciais; 2 Expressão do writ coletivo $N^{\circ}$ 143.641/SP; 3 Aspectos teórico-filosóficos da decisão e os "Protagonismos"; 4 Considerações finais; Referências.

RESUMO: Observa-se, nacontemporaneidade, umacrise profunda na homogeneidade das decisões judiciais no Brasil. Essa conjuntura provém das tensões entre teses internacionais e, muitas vezes, de interpretações errôneas de teorias externas. Diante deste contexto, o artigo visa a analisar o habeas corpus coletivo $\mathrm{n}^{0} 143.641 / \mathrm{SP}$ com o objetivo de individualizar essas tensões, identificando a natureza jurídica do julgado. Essa análise comportará os fundamentos pautados pela Defensoria Pública da União enquanto impetrante, o Parecer da Procuradoria Geral da União e os critérios do voto do relator ministro Ricardo Lewandowski. Ainda, compreenderá o exame de conceitos como "judicialização da política", "ativismo judicial" e "hermenêutica". O método de abordagem utilizado foi o hermenêutico-fenomenológico.

PALAVRAS-CHAVE: Decisão judicial; Direito penal; Cárcere feminino; Habeas corpus coletivo.

\section{VICISSITUDES AND TRIUMPHS OF THE COLLECTIVE HABEAS CORPUS 143.641/SP: AGENCY AND JUDICIAL ACTIVISM?}

ABSTRACT: There has been currently a deep crisis within the homogeneity of juridical decisions in Brazil. The above is due to the tensions between international theses and, frequently, the wayward interpretation of these theories. Current analysis investigates the collective habeas corpus 143.641/SP to pinpoint tensions and identify the juridical nature of the matter judged. The analysis will comprise the bases foregrounded by the Prosecutor as petitioner, the opinion of the Attorney General and the vote criteria of the minister Ricardo Lewandowski. An analysis of the concepts "judicialization of politics", "judicial activism" and "hermeneutics" will be undertaken through the hermeneutic and phenomenological approach.

KEY WORDS: Judicial decision; Penal Law; Female prison; Collective habeas corpus.

\footnotetext{
Doutor em Direito (UNISINOS). Professor do Mestrado em Direitos Humanos (UNIJUÍ) e dos Cursos de Graduação em Direito (UNISINOS e UNIJUÍ). Líder do Grupo de Pesquisa Biopolítica e Direitos Humanos (CNPq). E-mail: madwermuth@gmail.com

** Graduanda em Direito Pela UNIJUÍ; Bolsista FAPERGS; Membro do Grupo de Pesquisa Biopolítica e Direitos Humanos (CNPq). Brasil.
} 


\section{VICISITUDES Y TRIUNFOS DEL HABEAS CORPUS COLECTIVO 143.641/SP: ¿PROTAGONISMOS Y ACTIVISMO JUDICIAL?}

RESUMEN: Se observa, hoy día, una crisis profunda en la homogeneidad de las decisiones judiciales en Brasil. Esa coyuntura proviene de las tensiones entre tesis internacionales y, muchas veces, de interpretaciones erróneas de teorías externas. Delante de este contexto, el artículo tiene por objetivo analizar el habeas corpus colectivo $\mathrm{n}^{\mathrm{O}}$ 143.641/SP con el objetivo de individualizar esas tensiones, identificando la naturaleza jurídica del juzgado. Ese análisis comportará los fundamentos pautados por la Defensoría Pública de la Unión mientras impetrante, el Parecer de la Procuraduría General de la Unión y los criterios del voto del relator ministro Ricardo Lewandowski. Aún, comprenderá el examen de conceptos como "judicialización de la política", "activismo judicial" y "hermenéutica". El método de abordaje utilizado fue el hermenéutico-fenomenológico.

PALABRAS CLAVE: Decisión judicial; Derecho penal; Cárcel femenino; Habeas corpus colectivo.

\section{CONSIDERAÇÕES INICIAIS}

O conflito gerado pela heterogeneidade de decisões nos tribunais contemporâneos gera diversas discussões no âmbito jurídico e, por via de consequência, uma busca incessante pela segurança jurídica no contexto da democracia constitucional. Nesse contexto, inserem-se outros meios diversos do que a mera aplicação da lei em sentido estrito para resolução de antagonismos como, por exemplo, o uso da analogia, dos denominados "princípios gerais do direito"03, dos princípios constitucionais, da jurisprudência, da doutrina, de métodos de hermenêutica etc.

Essas tensões, em alguns casos, originam inovações jurídicas, como será elucidado pelo presente estudo, cujo objeto é o babeas corpus $\mathrm{n}^{0} 143.641 / \mathrm{SP}$. Tal remédio constitucional é previsto a partir de uma perspectiva de tutela individual

\footnotetext{
${ }^{03}$ Recepções errôneas de teorias internacionais como a teoria da argumentação, o realismo norte-americano e a jurisprudência de valores, fazem surgir o fenômeno do pan-principiologismo, neologismo criado por Lenio Streck. Esse contexto potencializa a ocorrência do ativismo no campo do Poder Judiciário. Os conflitos gerados pela colisão de princípios gerais do direito no Brasil são solucionados por meio de uma "ponderação direta”, em que não há mais a distinção entre ponderação e subsunção, constituindo-se assim, verdadeiros decisionismos. STRECK, Lenio Luiz. O pan-principiologismo e o sorriso do lagarto. Conjur. Disponível em http://www.conjur.com.br/2012-mar-22/senso-incomum-pan-principiologismo-sorriso-lagarto. Acesso em: 11 set. 2018.
} 
do direito de liberdade, não existindo sua previsão legal na modalidade coletiva, seja na Constituição, seja na legislação infraconstitucional. Essa é apenas uma das controvérsias que suscitou grande polêmica no meio jurídico brasileiro - fomentada, em boa medida, pela mídia - em fevereiro do ano de $2018^{04}$.

O exame do caso que deu origem ao sobredito habeas corpus será realizado a partir dos fundamentos utilizados pela Defensoria Pública da União enquanto impetrante da medida, do Parecer da Procuradoria Geral da União e dos critérios mais pontuais constantes no voto do relator ministro Ricardo Lewandowski. Para a compreensão da natureza jurídica da decisão, conceitos como "judicialização da política", "ativismo judicial" e "hermenêutica" serão elucidados, observando-se a atuação dos tribunais nas sociedades contemporâneas.

Por meio da pesquisa alicerçada no método fenomenológico, será possível estabelecer parâmetros hermenêuticos-filosóficos que constituem a resposta, ainda que parcial, da problemática desta investigação: quais são as vicissitudes e os triunfos contidos no babeas corpus coletivo 143.641/SP para a atual conjuntura do sistema penitenciário feminino no Brasil? Primeiramente, será analisado o habeas corpus coletivo e os argumentos que deram sustentação à sua impetração, analisandose, também, o parecer da Procuradoria Geral da União e o voto do ministro relator do Supremo Tribunal Federal. Em seguida, serão explanadas as principais consequências teórico-práticas do julgado. Nesse prisma, este artigo visa a analisar o writ supracitado em seus aspectos elementares, a fim de individualizar as tensões a partir dele estabelecidas no cenário jurídico-penal brasileiro.

\footnotetext{
${ }^{04}$ Em novembro de 2016, Adriana Ancelmo - esposa de Sérgio Cabral, ex-governador do Rio de Janeiro - foi presa através da Operação Calicute. Três meses após ser presa, à Adriana foi concedida a prisão domiciliar por força do art. 318, V do CPP. Em novembro de 2017, tal decisão foi anulada pelo TRF da $2^{\mathrm{a}}$ Região, retornando a ex-primeira-dama para o regime fechado. Decorrido um mês, Adriana voltou para o regime domiciliar, pelos mesmos fundamentos, agora ratificados por decisão do Ministro Gilmar Mendes que referiu que as condições econômicas sustentadas pela paciente não poderiam ser utilizadas em seu desfavor. CONJUR. Adriana Ancelmo consegue HC no Supremo e voltará à prisão domiciliar. São Paulo: Consultor Jurídico ConJur, 2017. Disponível em: https://www.conjur.com.br/2017-dez-18/adriana-ancelmo-hc-stf-voltara-prisaodomiciliar. Acesso em: 11 set. 2018. Recentemente, o pedido do Ministério Público Federal da substituição da prisão domiciliar pelo uso de tornozeleira eletrônica e recolhimento domiciliar aos finais de semana foi atendido pelo juiz Marcelo Bretas, da $7^{a}$ Vara Criminal Federal do Rio de Janeiro. IG SÃO PAULO. Atendendo a um pedido do Ministério Público Federal, Marcelo Bretas concedeu a advogada que ela saia de casa nos dias de semana; entenda. São Paulo: Último Segundo - iG, 2018. Disponível em: http://ultimosegundo.ig.com.br/ politica/2018-08-28/adriana-ancelmo-tornozeleira-eletronica.html. Acesso em: 11 set. 2018.
} 


\section{EXPRESSÃO DO WRIT COLETIVO No 143.641/SP}

O caso ora apresentado se trata de um habeas corpus coletivo que gerou, recentemente, grande repercussão no cenário jurídico-penal e na mídia brasileira. Os pacientes desse writ são "todas as mulheres submetidas à prisão cautelar no sistema penitenciário nacional, que ostentem a condição de gestantes, de puérperas ou de mães com crianças com até 12 anos de idade sob sua responsabilidade, e das próprias crianças" ${ }^{\circ}$.

A medida foi impetrada pela Defensoria Pública da União (DPU), que contou, como assistentes, com membros do coletivo de advogados em Direitos Humanos (CADHu). Figuram como autoridade coatoras, na petição inicial, os Juízes(as) das Varas Criminais Estaduais, Tribunais dos Estados e do Distrito Federal e Territórios, Juízes(as) Federais com Competência Criminal, Tribunais Regionais Federais, Superior Tribunal de Justiça (STJ).

É sabida pelo STF a situação de precariedade e superlotação dos presídios brasileiros na atualidade ${ }^{06}$. Tanto é verdade que o STF reconheceu o "estado de coisas inconstitucional" no julgamento da liminar da ADPF $n^{0} 347^{07}$. São escancaradas as condições de deficiência no encarceramento para homens, as quais já foram, inclusive, reconhecidas no cenário internacional por meio da atuação do Sistema Interamericano de Direitos Humanos - ex vi dos casos envolvendo o Complexo Penitenciário de Pedrinhas, no Maranhão, e do Presídio Central de Porto Alegre, no Rio Grande do Sul ${ }^{08}$.

Assim sendo, não é preciso muito esforço para vislumbrar quais as dificuldades pelas quais passam as mulheres nos presídios brasileiros a elas destinados - quando destinados -, evidentemente mais precários em razão do não

\footnotetext{
${ }^{05}$ BRASIL. Supremo Tribunal Federal. Habeas Corpus no 143.641 São Paulo, 2018. Disponível em: http://www. stf.jus.br/arquivo/cms/noticiaNoticiaStf/anexo/HC143641final3pdfVoto.pdf. Acesso em: 25 mar. 2018, p. 1.

${ }^{06}$ O próprio Conselho Nacional de Justiça (2012, p. 109), já em 2012, anunciava que "vários estabelecimentos prisionais do Estado não são dignos sequer de abrigar animais irracionais ferozes".

${ }^{07}$ BRASIL. Supremo Tribunal Federal. Arguição de Descumprimento de Preceito Fundamental 347/DF, 2015. Disponível em: http://redir.stf.jus.brqpagina-dorpubqpaginador.jsp?docTP $=\mathrm{TP} \& d o c \mathrm{ID}=10300665$. Acesso em: 14 nov. 2017.

${ }^{08}$ COMISSÃO INTERAMERICANA DE DIREITOS HUMANOS. Resolução 11/2013. Medida Cautelar no 367-13. Assunto: Pessoas Privadas de Liberdade no "Complexo Penitenciário de Pedrinhas", Brasil. 16 de Dezembro de 2013a. Disponível em: https://www.oas.org/es/cidh/decisiones/pdf/MC367-13-pt.pdf. Acesso em: 09 jan. 2017. COMISSÃO INTERAMERICANA DE DIREITOS HUMANOS. Resolução 14/2013. Medida Cautelar $\mathrm{n}^{0}$ 8-13. Assunto: Pessoas Privadas de Liberdade no "Presídio Central de Porto Alegre", Brasil. 30 de Dezembro de 2013b. Disponível em: http://www.ajuris.org.br/sitenovo/wp-content/uploads/2014/01/Medida-CautelarPres\%C3\%ADdio-Central-30-12-2013.pdf. Acesso em: 09 jan. 2017.
} 
atendimento às especificidades da condição feminina. Conforme salienta Braga ${ }^{09}$, "longe da soberania da lei, o chão da prisão é feito de violações de direitos, que caracterizam o passado e o presente do sistema prisional brasileiro e se acentuam em relação às mulheres encarceradas." Isso decorre, em boa medida, de um déficit histórico em relação ao planejamento/execução de políticas públicas voltadas ao cárcere feminino no Brasil, considerando-se que as políticas penitenciárias foram pensadas levando em consideração a população majoritária das prisões: os homens.

Foi levando em consideração estas peculiaridades do cárcere feminino que a Defensoria Pública da União (DPU), juntamente com os assistentes do CADHu e demais custos vulnerabilis e amicus curiae impetraram o HC 143.641. Ao aprisionarem preventivamente mulheres que se enquadram nos casos já previstos pelo nos incisos IV e V do art. 318 do Código de Processo Penal (alteração dada pela li $n^{0} .13 .157 / 2016$, considerado o Marco Legal da Primeira Infância), o Estado lhes subtrai diversos direitos, dentre os quais está "o acesso a programas de saúde pré-natal, assistência regular na gestação e no pós-parto"10. Ainda, essa atitude priva as crianças nascidas no cárcere de um desenvolvimento saudável, o que "constitui tratamento desumano, cruel e degradante, que infringe os postulados constitucionais relacionados à individualização da pena, à vedação de penas cruéis e, ainda, ao respeito à integridade física e moral da presa." 11

No sistema carcerário brasileiro, milhares de mulheres vivem gestações, partos e maternidades em situações extremamente precárias, sendo que seus filhos formam uma parcela "invisível" da população prisional. ${ }^{12}$ Em pesquisa multidisciplinar de abrangência nacional realizada no âmbito da Escola Nacional de Saúde Pública (ENSP) da Fiocruz, foi analisada a jurisprudência dos Tribunais Superiores brasileiros a respeito do tema da maternidade na prisão entre os anos de 2002 a 2012. Os dados coletados apontaram para uma "invisibilidade da questão", que poderia ser explicada "pelo menor percentual de mulheres no universo prisional, pelo preconceito referente à garantia dos direitos das presas ou por dificuldades de efetivo acesso à Justiça, que envolvem motivações e acessibilidade das próprias

\footnotetext{
${ }^{09}$ BRAGA, Ana Gabriela Mendes. Entre a soberania da lei e o chão da prisão: a maternidade encarcerada. Revista Direito GV, São Paulo, vol. 11, n. 2, p. 523-546, jul/dez. 2015. Disponível em: http:/bibliotecadigital.fgv.br/ojs/ index.php/revdireitogv/article/view/58121/56586. Acesso em: 25 ago. 2018, p. 531.

${ }^{10}$ BRASIL. op. cit., p. 4.

${ }^{11}$ Idem. p. 4.

${ }^{12}$ FALCADE, Ires Aparecida (org.). Mulheres invisíveis: por entre muros e grades. Curitiba: JM Editora e Livraria Jurídica, 2016.
} 
presas à Defensoria Pública, aos advogados e ao Ministério Público." ${ }^{13}$ A partir desses resultados, Simas et. al. ${ }^{14}$ salientam que a jurisprudência majoritária do Supremo Tribunal Federal e do Superior Tribunal de Justiça "caminhou no sentido de reafirmar o discurso da segurança e manutenção da ordem em face do direito indisponível e irrenunciável da criança à alimentação, à saúde e à convivência com sua mãe”. O fundamento das decisões, na maior parte dos casos, leva em consideração o caráter hediondo do delito (invariavelmente de tráfico), que prevalece como maior valor ponderado.

Para além dos malefícios à mulher presa, a prisão de gestantes, puérperas e mães evidencia, também, o rompimento do princípio da intranscendência (ou pessoalidade) da pena, uma vez que, conforme o art $5^{\circ}$, XLV, da Constituição Federal "nenbuma pena passará da pessoa do condenado, podendo a obrigação de reparar o dano e a decretação do perdimento de bens ser, nos termos da lei, estendidas aos sucessores e contra eles executadas, até o limite do valor do patrimônio transferido". [grifou-se] De acordo com Zaffaroni, Batista, Alagia e Slokar ${ }^{15}$, o princípio em questão é basilar de todo Estado democrático de Direito, uma vez que "o Estado de polícia estende a responsabilidade a todos que cercam o infrator, pelo menos por não terem denunciado sua atividade, e considera sua família perigosa, porque seus membros podem vingá-lo." Já em um Estado democrático de Direito, "a responsabilidade penal deve ser individual e não pode transcender a pessoa do delinquente." Ocorre que, mesmo em um ambiente tal, a "transcendência do poder punitivo na direção de terceiros é, de fato, inevitável: a comunicação, o conhecimento, a estigmatização, a queda dos rendimentos etc., são todos efeitos que inevitavelmente alcançam a família do simples acusado e mesmo outras pessoas." Na legislação brasileira há dispositivos que visam a atenuar esses efeitos da pena em relação a terceiros, a exemplo do auxílio-reclusão, de natureza previdenciária, regido pelo art. 80 da lei no 8.2131991 . Os sobreditos autores referem que "um efeito transcendente de prisonização - sem embargo da tímida previsão legal da visita íntima (art. 40, inc. X, LEP), na prática subordinada à maior ou menor liberalidade da administração - é a privação de relações sexuais, que deixa ao cônjuge ou companheiro não-institucionalizado a opção entre abstinência ou dissolução do vínculo afetivo."

\footnotetext{
13 SIMAS, Luciana; VENTURA, Miriam; BAPTISTA, Michelly Ribeiro; LAROUZÉ, Bernard. A jurisprudência brasileira acerca da maternidade na prisão. Revista Direito GV, São Paulo, v. 11, n. 2, p. 547-572, jul/dez 2015. Disponível em: http:/bibliotecadigital.fgv.br/ojs/index.php/revdireitogv/article/view/58122/56587. Acesso em: 25 mar. 2018, p. 555.

${ }^{14}$ Idem. p. 557.

15 ZAFFARONI, Eugenio Raúl; BATISTA, Nilo Batista; ALAGIA, Alejandro; SLOKAR, Alejandro. Direito penal brasileiro: primeiro volume. Teoria Geral do Direito Penal. 2. ed. Rio de Janeiro: Revan, 2003, p. 232.
} 
Em relação ao tema, é evidente que as crianças nascidas no cárcere são, desde o nascimento, privadas da convivência em sociedade, dado que limitadas pelos muros de uma instituição total, o que significa uma enorme discrepância entre o desenvolvimento de uma criança "livre" e uma criança nascida em um espaço intramuros. De acordo com Armelin ${ }^{16}$, o ambiente carcerário não oferece meios adequados de locomoção e tampouco objetos passíveis de utilização em atividades espontâneas. Isso, conjugado com a limitação espacial em si, acaba por aprisionar mais as crianças que as suas próprias mães, o que interfere de maneira negativa no desenvolvimento do filho.

Considerando esses fatores, a tendência era que, a partir de 2016, com a edição da lei $n^{0} 13.157 / 2016$, houvesse uma preferência pela prisão domiciliar nos casos em questão. Entretanto, tem ocorrido uma discrepância nas decisões, evidenciando-se que metade dos pedidos nesse sentido formulados têm sido indeferidos pela magistratura nacional. Tem-se notado alto nível de heterogenia na aplicação do art. 318 do Código de Processo Penal (CPP), principalmente pela alta incidência de prisões preventivas para as mulheres negras e de famílias pobres. Dessa forma, aduziu a DPU que a gravidade do delito, bem como demais fatores, não poderiam ser usados como critério de manutenção da prisão preventiva.

O Judiciário deve sempre nortear-se pelo princípio da excepcionalidade e pelo caráter de ultima ratio da prisão preventiva, a qual "será determinada quando não for cabível a sua substituição por outra medida cautelar (art. 319)", nos termos do art. $282, \S 6^{\circ}$, do CPP. Os impetrantes do HC em tela frisaram que, diante do reconhecimento do "estado de coisas inconstitucional", a natureza das decisões do STF demonstrariam um movimento ao deferimento das substituições perante a mera inocorrência de qualquer um dos requisitos presentes no art. 312 do CPP.

Outrossim, arguiram que, apesar de existirem disposições jurídicas na Lei de Execução Penal (LEP) que garantem o suporte clínico da relação entre a mãe e o bebê, os atuais estabelecimentos prisionais não estão preparados para efetivar essa garantia. Aduziram que esse despreparo já condenou o Brasil perante o Comitê para a Eliminação de todas as Formas de Discriminação contra a Mulher, no âmbito do caso Alyne da Silva Pimentel versus Brasil ${ }^{17}$. Nesse sentido, é incabível imputar

\footnotetext{
${ }^{16}$ ARMELIN, Bruna Dal Fiume. Filhos do cárcere: estudo sobre as mães que vivem com seus filhos em regime fechado. Revista da Graduação, v. 3, n. 2, 2010. Disponível em: http://revistaseletronicas.pucrs.br/ojs/index. php/graduacao/article/viewFile/7901/5586. Acesso em: 27 ago. 2018, p. 12-13.

${ }^{17}$ REPRODUCTIVE RIGHTS. Caso de Alyne da Silva Pimentel Teixeira ("Alyne") v. Brasil, 2014. Disponível em: https:/www.reproductiverights.org/sites/crr.civicactions.net/files/documents/LAC_Alyne_Factsheet_ Portuguese_10\%2024\%2014_FINAL_0.pdf. Acesso em: 10 set. 2018.
} 
regime mais gravoso à condenada se o Estado não é capaz de oferecer as referidas condições, afinal, deve ser o direito de punir mitigado, e não a liberdade individual.

Ao impetrar o remédio constitucional, a DPU afirmou que, ainda que não expresso no ordenamento jurídico brasileiro, é cabível a impetração multitudinária de HC é admissível com base no art. 25, I, da Convenção Americana de Direitos Humanos. Esse dispositivo permite e incentiva procedimentos coletivos por razões de celeridade e economia processual. Tal asserção por parte da impetrante denota a importância do direito internacional para questões de direito público interno, uma vez que o processo coletivo no Brasil ainda é incipiente.

Para ratificar o cabimento do feito, citaram casos processados no STF que tiveram andamento regular e nos quais não houve a identificação específica dos pacientes, o que permitiria a sua identificação genérica. Ainda, apontaram que as ações coletivas, como o mandado de segurança e o mandado de injunção coletivos, demonstram: "(i) a caminhada das ações constitucionais em direção às soluções coletivas e (ii) o reconhecimento da representatividade da Defensoria Pública" ${ }^{\text {" }}$.

Com efeito, de acordo com a lição de Geraldo Prado ${ }^{19}$, no Brasil é possível impetrar HC coletivo desde a incipiente República: "à luz do art. 340 do Código de Processo Criminal do Império, e depois do advento das leis que proscreveram o tráfico de escravos e promulgaram o 'ventre livre", o HC multitudinário, "que integrava uma das muitas formas das chamadas ações de liberdade", era empregado para "a proteção de negros 'suspeitos', que perambulavam pela cidade do Rio de Janeiro, sem cometer crime algum." No mesmo sentido, Manoel Godofredo d'Alencastro Autran ${ }^{20}$, em sua clássica obra, ao versar sobre a "amplitude do habeas corpus", salienta a possibilidade de ele ser impetrado em favor de paciente de violência "collectivo ou singular", sendo que "quer n'um, quer n'outro caso lhe é indisputável o direito de usar do habeas-corpus."

Nada impede, portanto, no âmbito da doutrina brasileira do $\mathrm{HC}^{21}$, a sua impetração multitudinária quando feita em benefício de grupos de indivíduos que se encontram em uma situação fática e jurídica similar. Deve-se, nesses casos,

\footnotetext{
$\overline{18}$ BRASIL, op. cit. 2018 , p. 11.

19 PRADO, Geraldo. Parecer: Habeas Corpus Coletivo impetrado em favor dos "flanelinhas". Disponível em: http://emporiododireito.com.br/tag/habeas-corpus-coletivo/. Acesso em: 08 jun. 2017, s.p.

${ }^{20}$ AUTRAN, Manoel Godofredo d'Alencastro. Do Habeas Corpus e seo recurso ou compilação das disposições legaes, e decisões do Governo a respeito, em exposição simples e methodica, seguida de um formulário do respectivo processo, e de um índice alphabetico. Rio de Janeiro: Garnier, 1879. Disponível em: http://www.stf. jus.br/bibliotecadigital/OR/40968/pdf/40968.pdf. Acesso em: 19 mar. 2018, p. 11.

${ }^{21}$ BARBOSA, Rui. República: Teoria e Prática: Textos doutrinários sobre direitos humanos e políticos consagrados na Primeira Constituição Republicana. Petrópolis: Vozes, 1978.
} 
"avaliar a plausibilidade da existência do coletivo, ainda que informal". Isso significa, em termos práticos, que “o que deve ser 'determinado' [...] é a 'coletividade' e não seus membros [...] e a plausibilidade dessa determinação da coletividade resulta da plausibilidade da própria ameaça à liberdade de locomoção dos membros da mencionada coletividade." ${ }^{22}$ Trata-se, nas palavras de Lordelo ${ }^{23}$, de observar, como em qualquer outra ação coletiva, se há "uma adequada delimitação do grupo favorecido, por meio da especificação da questão comum (o que os americanos chamam de commonality)."

Nesses termos, a tutela coletiva de direitos evidencia-se enquanto condição de possibilidade para superar as barreiras que são opostas ao acesso à justiça de uma coletividade que, na clássica visão de Capelleti e Garth ${ }^{24}$, envolve pessoas que "podem estar dispersas, carecer da necessária informação ou simplesmente ser incapazes de combinar uma estratégia comum." Assim, além de representarem um importante mecanismo de descongestionamento do sistema judiciário, as demandas coletivas também evidenciam maior preocupação com a ideia de isonomia entre os jurisdicionados. Isso porque, "a um vasto contingente de ações [individuais] corresponderia um elevado número de decisões, capazes de oferecer soluções contraditórias a um mesmo problema", de modo que, em situações tais, "o recurso ao Judiciário pode se converter em verdadeira loteria, em que a maior ou menor sorte do litigante é determinada no momento da distribuição da ação." ${ }^{25}$

Do mesmo modo, como assevera Prado $^{26}$, no campo processual penal, a lei autoriza, tanto no que diz respeito aos requisitos da denúncia (art. 41, CPP), quanto no que se refere à citação editalícia (art. 352, III, CPP), que, nas hipóteses em que não se dispõe do nome completo do acusado, sejam indicados os seus "sinais característicos" a fim de que possa ser formalmente acusado. O autor refere, como exemplo dessa indeterminação, a expedição, pelo juiz da $39^{\mathrm{a}}$ Vara Criminal do Rio de Janeiro, nos autos da Medida Cautelar de Busca e Apreensão autuada sob o $\mathrm{n}^{\mathrm{o}}$ 0101343-46.2014.8.19.0001, de mandado de busca e apreensão genérico, que foi

$\overline{22}$ PRADO, Geraldo. op. cit. 2015, s. p.

${ }^{23}$ LORDELO, João. O habeas corpus coletivo na jurisprudência do STF: comentários ao julgamento do HC $\mathrm{n}^{\mathrm{o}}$ 143.641, 2018. Disponível em: https://www.joaolordelo.com/single-post/2018/03/03/O-habeas-corpuscoletivo-na-jurisprud\%C3\%AAncia-do-STF-coment\%C3\%A1rios-ao-julgamento-do-HC-n\%C2\%BA-143641. Acesso em: 15 mar. 2018.

${ }^{24}$ CAPELLETI, Mauro; GARTH, Bryant. Acesso à justiça. Trad. Ellen Gracie Northfleet. Porto Alegre: Sergio Antonio Fabris, 1988, p. 27.

${ }^{25}$ SARMENTO, Daniel; BORGES, Ademar; Gomes, Camilla. Parecer: O Cabimento do Habeas Corpus Coletivo na Ordem Constitucional Brasileira. 2015. Disponível em: https://www.conjur.com.br/dl/parecer-hc-coletivo.pdf. Acesso em: 13 mar. 2018, p. 5.

${ }^{26}$ PRADO, Geraldo. op. cit. 2015, s. p. 
endereçado, indistintamente, às residências do Complexo da Maré. A partir desta ilação, a impetração de habeas corpus em favor de uma coletividade também se mostraria adequada em homenagem ao princípio da paridade de armas no processo penal.

Afinal,

se é possível reprimir coletivamente, isto é, valendo-se as forças de segurança de dispositivos que não as obrigam a individualizar e nomear as pessoas e os bens fundamentais (domicílio, parcela vital do patrimônio pessoal etc.) que são afetados pelas ações repressivas, exigir-se sempre, em qualquer caso, a determinação dos afetados resultaria em uma diabólica inversão de ônus. ${ }^{27}$

Efetivamente, no que diz respeito à tutela coletiva do status libertatis, deve-se considerar que tal direito, em determinados situações, pode ser ameaçado ou cerceado em relação a um número indeterminado de pessoas. A jurisprudência brasileira já possui precedentes em relação ao tema. Por exemplo, no habeas corpus $\mathrm{n}^{\mathrm{o}}$ 142.513/ES, o Superior Tribunal de Justiça (STJ) entendeu pela concessão da ordem coletiva aos prisioneiros que estavam cumprindo pena em contêineres, substituindo-se a pena por prisão domiciliar ${ }^{28}$. Já no habeas corpus $\mathrm{n}^{0} 207.720 / \mathrm{SP}$, o STJ concedeu a ordem coletiva às crianças e adolescentes de Cajuru-SP, atingidas pela determinação de "toque de recolher" instituído por portaria da Vara da Infância e da Juventude da Comarca ${ }^{29}$.

Os casos mencionados evidenciam, como ressaltam Sarmento, Borges e Gomes $^{30}$, a importância da tutela coletiva do status libertatis em um país como o Brasil, no qual "o braço penal do Estado tem uma clientela bem definida, dirigindo o processo de criminalização para comportamentos típicos das camadas sociais subalternas e concentrando sua atuação repressiva sobre os socialmente marginalizados."

$\mathrm{Na}$ impetração do HC ora analisado, os autores atentaram, também, ao fato de que grande parte das pessoas presas preventivamente no Brasil são absolvidas, ou têm sua pena substituída por penas alternativas, o que demonstra certa incoerência

\footnotetext{
${ }^{27}$ PRADO, Geraldo. op. cit. 2015, s. p.

${ }^{28}$ BRASIL. Superior Tribunal de Justiça. HC: 142513 ES 2009/0141063-4, Relator: Ministro Nilson Naves, Data de Julgamento: 23/03/2010, T6 - SEXTA TURMA, Data de Publicação: DJe 10/05/2010.

29 BRASIL. Superior Tribunal de Justiça. HC: 207720 SP 2011/0119686-3, Relator: Ministro Herman Benjamin, Data de Julgamento: 01/12/2011, T2 - SEGUNDA TURMA, Data de Publicação: DJe 23/02/2012.

${ }^{30}$ SARMENTO, Daniel; BORGES, Ademar; Gomes, Camilla. op. cit. 2015, p. 7-8.
} 
e desnecessidade da aplicação da prisão preventiva como medida primeira. Foi nesse sentido que a impetrante e os assistentes embasaram suas alegações. Entretanto, a Procuradoria Geral da União (PGU) manifestou entendimento diverso pelas impossibilidades teóricas e jurídicas da aplicação do instituto escolhido (HC), conforme fundamentos abordados a seguir.

A Procuradoria Geral da União (PGU) opinou pelo não reconhecimento do feito, vez que a Suprema Corte já entendia que pacientes genéricos inviabilizavam a devida apreciação do constrangimento ilegal no caso fático. Alertou para o fato do objeto da decisão cuidar de direitos transindividuais, o que poderia ensejar a prescindibilidade do exame desse constrangimento no caso concreto. Em vista disso, o writ se mostraria inviável "ante a impossibilidade de concessão de ordem genérica, sem individualização do seu beneficiário e de expedição de salvo-conduto a um número indeterminado de pessoas" ${ }^{\text {"1 }}$.

No mesmo sentido, explicou que o art. $5^{\circ}$, inciso LXVIII, da Carta Magna confere uma proteção imediata e direta da liberdade de locomoção, e a concessão dessa ordem poderia converter-se em súmula vinculante ou instrumento de política pública criminal - importante consideração no que tange à aplicação da hermenêutica.

Outrossim, referiu que, pela inexistência de especificidade dos coatores, membros do Superior Tribunal de Justiça, seria incabível que tal fosse considerado coator. Portanto, incompetente o Supremo Tribunal Federal para julgar os pedidos. Isso porque a competência para julgar contida na Constituição Federal, em seu art. 102, inciso I, "d" e "i", é numerus clausus, ou seja, não admite a ampliação do rol exaustivo.

Ainda, afirmou que a mera condição de "maternidade" não poderia ensejar a concessão do benefício "porque o art. 318 do Código de Processo Penal não estabelece direito subjetivo automático, asseverando que o objetivo da norma é tutelar os direitos da criança, e não da mãe, cuja liberdade pode até representar um risco para esta." ${ }^{2}$ Atentou que, nesses casos, o Juízo das Execuções deve levar em conta a necessidade da prisão domiciliar, e não o contrário. Destarte, na ótica da PGU, trata-se de uma possibilidade, não uma obrigatoriedade.

Em sede de preliminar, foi deferido o cabimento do habeas corpus coletivo por analogia à legislação referente ao mandado de injunção coletivo. O ministro Lewandowski reiterou a importância do instituto, e asseverou que se deve extrair

\footnotetext{
$\overline{31}$ BRASIL, op. cit., 2018, p. 8.

32 Idem. p. 13.
} 
o máximo das suas potencialidades, "nos termos dos princípios ligados ao acesso à Justiça previstos na Constituição de 1988 e, em particular, no art. 25 do Pacto de São José da Costa Rica." ${ }^{33}$ Além disso, reconheceu a competência da Suprema Corte para o julgamento tendo em vista a pertinência constitucional da matéria.

Foi suscitado que o STF tem admitido a ampliação do uso de institutos processuais coletivos, como é o caso do frequente uso da Ação de Descumprimento de Preceito Fundamental (ADPF), e do mandado de injunção coletivo. Nesse condão, o ministro referenciou a doutrina a que se filia o jurista Ruy Barbosa - mencionada no tópico 2.1 -, em que, de tal modo "se existe um direito fundamental violado, há de existir no ordenamento jurídico um remédio processual à altura da lesão". ${ }^{4}$

Segundo o relator, a ação coletiva seria, possivelmente, a única solução factível para o caso concreto, até porque, diferentemente do que entende a Procuradoria-Geral da União, os pacientes são determináveis diante das informações obtidas pelo Departamento Penitenciário Nacional (DEPEN) e demais autoridades. Ainda, destacou o art. $654, \S 2^{\circ}$, do CPP, segundo o qual os juízes e Tribunais podem expedir, de ofício, ordem de habeas corpus, quando verificarem que alguém sofreu ou está na iminência de sofrer coação ilegal. Essa faculdade, em tese, ratifica a flexibilidade e o objetivo do remédio constitucional de combater, da forma mais célere e eficaz possível, ameaças e lesões à liberdade de locomoção. O relator referiu:

Considero fundamental, ademais, que o Supremo Tribunal Federal assuma a responsabilidade que tem com relação aos mais de 100 milhões de processos em tramitação no Poder Judiciário, a cargo de pouco mais de 16 mil juízes, e às dificuldades estruturais de acesso à Justiça, passando a adotar e fortalecer remédios de natureza abrangente, sempre que os direitos em perigo disserem respeito às coletividades socialmente mais vulneráveis. Assim, contribuirá não apenas para atribuir maior isonomia às partes envolvidas nos litígios, mas também para permitir que lesões a direitos potenciais ou atuais sejam sanadas mais celeremente. Ademais, contribuirá decisivamente para descongestionar o enorme acervo de processos sob responsabilidade dos juízes brasileiros. ${ }^{35}$

33 Ibidem. p. 19.

${ }^{34}$ BRASIL, op. cit., 2018, p. 16.

35 Idem. p. 20. 
No que tange ao mérito, o ministro relator salientou que, de fato, há uma deficiência estrutural no sistema prisional e que ela é muito séria, frisando que essa deficiência é excessivamente maior em relação às mulheres presas por conta de suas necessidades/especificidades, que são manifestamente distintas das dos homens. Especificamente no caso das gestantes, puérperas e mães, trata-se de uma situação em que a dignidade da pessoa humana é altamente ferida, tanto no que tange à mulher, quanto no que tange às crianças. Tal afirmativa do ministro é corroborada pelos levantamentos estatísticos trazidos na exordial, as quais evidenciam que "a população absoluta de mulheres encarceradas no sistema penitenciário cresceu $567 \%$ entre os anos 2000 e $2014 "{ }^{36}$, sendo que, "enquanto 52\% das unidades masculinas são destinadas ao recolhimento de presos provisórios, apenas $27 \%$ das unidades femininas têm esta finalidade" ${ }^{\prime 3}$, embora $30,1 \%$ da população prisional sejam feminina e estejam em prisão provisória.

O ministro frisou que existe uma grande deficiência nos indicadores e dados oficiais, o que inflama a invisibilidade dessas mulheres por uma questão histórica. Importante, igualmente, notar o perfil da mulher ou jovem encarcerada: tratam-se geralmente de "mulas do tráfico", sendo que $68 \%$ dessas cometeram crimes que não envolvem violência ou grave ameaça à pessoa ${ }^{38}$. O ministro afirmou que $41 \%$ dos presos no Brasil estão encarcerados sob caráter preventivo. Para agravar a situação, esses presos, ao final do processo, ou são absolvidos, ou são condenados a cumprir penas alternativas. Esse panorama reflete a conhecida "cultura do encarceramento", em que há uma inversão e até mesmo uma mitigação do princípio da presunção de inocência ${ }^{39}$.

Sobre o "estado de coisas inconstitucional" e a necessidade improrrogável da melhoria na estrutura carcerária, verifica-se que

[É] forte [a] violação de direitos fundamentais, alcançando a transgressão à dignidade da pessoa humana e ao próprio

\footnotetext{
${ }^{36}$ Ibidem. p. 23.

${ }^{37}$ Ibidem. p. 24.

38 INFOPEN MULHERES. Levantamento Nacional de Informações Penitenciárias: Infopen Mulheres - Junho de 2014. Brasília: Ministério da Justiça e Departamento Penitenciário Nacional, 2014. Disponível em: http:/ www.justica.gov.br/news/estudo-traca-perfil-da-populacao-penitenciaria-feminina-no-brasil/relatorio-infopenmulheres.pdf. Acesso em: 13 mar. 2018.

39 INFOPEN. Levantamento Nacional de Informações Penitenciárias: atualização - junho de 2016. Brasília: Ministério da Justiça e Segurança Pública e Departamento Penitenciário Nacional, 2017. Disponível em: http:// depen.gov.br/DEPEN/noticias-1/noticias/infopen-levantamento-nacional-de-informacoes-penitenciarias-2016/ relatorio_2016_22111.pdf. Acesso em: 13 mar. 2018.
} 
mínimo existencial justifica a atuação mais assertiva do Tribunal. [...] apenas o Supremo revela-se capaz, ante a situação descrita, de superar os bloqueios políticos e institucionais que vêm impedindo o avanço de soluções, o que significa cumprir ao Tribunal o papel de retirar os demais Poderes da inércia, catalisar os debates e novas políticas públicas, coordenar as ações e monitorar os resultados. ${ }^{40}$

Outros assuntos foram trazidos à pauta, como, por exemplo, a saúde materna, a saúde psicológica, o vínculo da primeira infância, a necessidade de assistência médica pré-natal e durante os partos, a "hiper-hipo-maternidade", ou seja, a alta regulação da maternidade seguida pela abrupta ruptura de vínculo, segundo Braga e Angotti ${ }^{41}$, a realidade em que vivem as mulheres e jovens presas (sofrem partos em solitárias, algemadas, sem assistência média, sem a presença de familiares ou qualquer comunicação), muitas mães perdem seus filhos para a adoção sem a oportunidade do contraditório e da ampla defesa, as crianças e respectivos guardiões muitas vezes são submetidos a revistas íntimas, e demais temas.

O ministro Lewandowski, em seu voto, afirmou que o que se verifica no chão da prisão

é a duríssima - e fragorosamente inconstitucional - realidade em que vivem as mulheres presas, a qual já comportou partos em solitárias sem nenhuma assistência médica ou com a parturiente algemada ou, ainda, sem a comunicação e presença de familiares. A isso soma-se a completa ausência de cuidado prénatal (acarretando a transmissão evitável de doenças graves aos filhos, como sífilis, por exemplo), a falta de escolta para levar as gestantes a consultas médicas, não sendo raros partos em celas, corredores ou nos pátios das prisões, sem contar os abusos no ambiente hospitalar, o isolamento, a ociosidade, o afastamento abrupto de mães e filhos, a manutenção das crianças em celas, dentre outras atrocidades. Tudo isso de forma absolutamente incompatível com os avanços civilizatórios que se espera tenham se concretizado neste século XXI. ${ }^{42}$

\footnotetext{
${ }_{40}$ ADPF 347 MC/DF apud BRASIL, op. cit., 2018, p. 22-23.

${ }^{41}$ BRAGA, Ana Gabriela Mendes; ANGOTTI, Bruna. O excesso disciplinar: da hipermaternidade à hipomaternidade no cárcere feminino brasileiro. Revista SUR, v.12 n.22, p. 229-239, 2015. Disponível em: https://bdjur.stij.jus. br/jspui/bitstream/2011/101231/hipermaternidade_hipomaternidade_carcere_braga.pdf. Acesso em: 22 ago. 2018.

${ }^{42}$ BRASIL, op. cit., 2018, p. 15.
} 
Também, restou ressaltado pelo ministro que o princípio da intranscendência da pena efetivamente está sendo desrespeitado ao imputar o regime mais gravoso. $\mathrm{O}$ ministro apontou que diante da confusão de parâmetros contida na palavra "poderá" do caput do art. 318 do CPP, a melhor saída seria conceder a ordem para evitar arbitrariedades judiciais e supressões de direitos "típica de sistemas jurídicos que não dispõem de soluções coletivas para problemas estruturais. ${ }^{\text {‘3 }}$ Diante do exposto, foi concedida a ordem para

Determinar a substituição da prisão preventiva pela domiciliar - sem prejuízo da aplicação concomitante das medidas alternativas previstas no art. 319 do CPP - de todas as mulheres presas, gestantes, puérperas ou mães de crianças e deficientes, nos termos do art. $2^{\circ}$ do ECA e da Convenção sobre Direitos das Pessoas com Deficiências (Decreto Legislativo 186/2008 e Lei 13.146/2015), relacionadas neste processo pelo DEPEN e outras autoridades estaduais, enquanto perdurar tal condição, excetuados os casos de crimes praticados por elas mediante violência ou grave ameaça, contra seus descendentes ou, ainda, em situações excepcionalíssimas, as quais deverão ser devidamente fundamentadas pelo juízes que denegarem o benefício. [...] [E estender] a ordem, de ofício, às demais as mulheres presas, gestantes, puérperas ou mães de crianças e de pessoas com deficiência, bem assim às adolescentes sujeitas a medidas socioeducativas em idêntica situação no território nacional, observadas as restrições previstas no parágrafo acima. Quando a detida for tecnicamente reincidente, o juiz deverá proceder em atenção às circunstâncias do caso concreto, mas sempre tendo por norte os princípios e as regras acima enunciadas, observando, ademais, a diretriz de excepcionalidade da prisão. Se o juiz entender que a prisão domiciliar se mostra inviável ou inadequada em determinadas situações, poderá substituí-la por medidas alternativas arroladas no já mencionado art. 319 do CPP. ${ }^{44}$

O relator invocou, em todo seu voto, as Regras das Nações Unidas para o Tratamento de Mulheres Presas e Medidas Não Privativas de Liberdade para Mulheres Infratoras, também conhecidas como Regras de Bangkok, e refere que a atuação

43 Idem. p. 47.

${ }^{44}$ Ibidem. p. 47. 
do Tribunal é condizente com textos normativos como a Declaração Universal dos Direitos Humanos, o Pacto Internacional de Direitos Civis e Políticos, a Convenção Americana de Direitos Humanos e afins, garantindo a prudência na concessão da ordem.

\section{ASPECTOS TEÓRICO-FILOSÓFICOS DA DECISÃO E OS "PROTAGONISMOS"}

O objetivo deste tópico é introduzir conceitos como "protagonismo judiciário", "judicialização dos conflitos políticos", "politização dos conflitos judiciários", "hermenêutica" e "ativismo judicial", ainda que de maneira concisa - dentro dos limites de um artigo científico -, para fomentar uma reflexão dos contornos teórico-filosóficos do caso em cena.

Inicialmente, cumpre salientar que, em diversas situações do passado brasileiro, o protagonismo dos Tribunais era de cunho conservador. Evidenciava-se uma tendência discriminatória da agenda política progressista. Por outro lado, não se acompanhavam as inovações necessárias decorrentes das inevitáveis transformações sociais, econômicas e políticas. Nos tribunais contemporâneos, em alguns julgados, as práticas mais recentes, de modo diverso, imprimem um viés garantista mais ousado no que tange aos direitos dos cidadãos. Obviamente que essa afirmação comporta inúmeras ressalvas, as quais não serão abordadas no presente artigo ${ }^{45}$, mas o fato é que isso tem gerado um novo padrão no intervencionismo judiciário, o qual ocorre de forma mais intensa no domínio criminal do que em outras áreas. Assim, dirige-se aos protagonistas dos abusos de poder e aos agentes políticos ${ }^{46}$.

Esse cenário esboça um "novo protagonismo judiciário [que] partilha com o anterior uma característica fundamental: traduz-se num confronto com a classe política e com outros órgãos de poder soberano, nomeadamente com o Poder Executivo. ${ }^{״ 7}$ É por isso que se fala em judicialização dos conflitos políticos, que não se confunde com a politização dos conflitos judiciários, porque é "na matriz do Estado moderno [que] o Judiciário é uni poder político, titular de soberania [...] [e]

\footnotetext{
45 Sobre o tema, consultar: WERMUTH, Maiquel Ângelo Dezordi. O "anjo da história" e o expansionismo penal: rumo a um modelo totalitário? Revista Brasileira de Ciências Criminais, v. 140, p. 371-398, fev. 2018.

${ }^{46}$ SANTOS, Boaventura de Souza; MARQUES, Maria Manuel Leitão; PEDROSO, João. Os tribunais nas sociedades contemporâneas. s. a. . Disponível em: http://www.anpocs.org.br/portal/publicacoes/rbcs_00_30/rbcs30_07. htm. Acesso em: 31 jul. 2018.

${ }^{47}$ Idem. p. 1.
} 
só se assume publicamente como poder político na medida em que interfere com outros poderes políticos”48 ${ }^{\$}$, sendo, assim, a política judiciária característica matricial da modernidade.

Esses fenômenos não constituem novidade no campo jurídico, e, segundo Boaventura de Sousa Santos, Maria Manuel Leitão Marques e João Pedroso ${ }^{49}$, sempre são suscitadas três questões nessa temática: a legitimidade, a capacidade e a independência. No campo da legitimidade - próprio de regimes democráticos trata-se da preocupação com a representação política obtida eleitoralmente, posto que majoritariamente os(as) magistrados(as) não são eleitos - e aqui se questiona o cunho democrático da sua participação.

No que tange à questão da capacidade, a problemática é a eficácia do uso dos recursos públicos que os tribunais dispõem - e que muitas vezes não dispõem. No caso de escassez de recursos - como é o caso brasileiro no âmbito dos presídios, sejam masculinos, femininos ou mistos - os tribunais acabam "à mercê da boa vontade de serviços que não estão sob sua jurisdição e, sempre que tal boa vontade falta, repercute direta e negativamente na própria eficácia da tutela judicial" ${ }^{\text {} 0}$.

Por fim, no que diz respeito à questão da independência dos tribunais, nela reside um dos pilares do constitucionalismo do Estado moderno. A independência bifurca-se nos seguintes aspectos: legitimidade e capacidade. No que se refere à legitimidade, há discussões sobre a mitigação da independência do Poder Judiciário, $\mathrm{e}$, no que tange à capacidade, o mesmo Poder se vê constantemente refém dos outros poderes por razões de natureza orçamentária, o que interfere frequentemente na boa execução de suas funções. Essas três questões suscitadas pelo protagonismo judiciário assumem papéis de suma importância nos momentos em que os tribunais assumem um protagonismo social e político.

Sempre é necessário analisar o contexto em que as diferentes temáticas se inserem em razão das suas repercussões. Desse modo, serão circunstanciadas as proposições a que estão incorporadas naquilo que compete à presente discussão. No plano sociopolítico das sociedades modernas, é possível identificar três importantes períodos: Estado liberal, Estado-providência, e a crise do Estadoprovidência (período atual). Para os limites deste artigo cabe a análise da crise do Estado-providência.

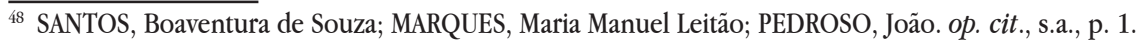

${ }^{49}$ Idem.

${ }^{50}$ Ibidem. p. 2.
} 
A crise no Estado-providência se deu em meados de 1970 e perdurou por toda década de 1980. São numerosas as suas manifestações, quais sejam:

Incapacidade financeira do Estado para atender às despesas sempre crescentes da providência estatal, tendo presente 0 conhecido paradoxo de esta ser tanto mais necessária quanto piores são as condições para a financiar [...]; a criação de enormes burocracias que acumulam um peso político próprio, que lhes permite funcionar com elevados níveis de desperdício e de ineficiência; a clientelização e normalização dos cidadãos cujas opções de vida (de atividade e de movimentos) ficam sujeitas ao controle e à supervisão de agências burocráticas despersonalizadas. ${ }^{51}$

Ademais, contribuíram para o aprofundamento da crise do modelo de Estado em questão as alterações nos sistemas produtivos e na regulação do trabalho a partir das sucessivas revoluções no campo tecnológico, a difusão do modelo neoliberal e de seu "credo" desregulamentador (notadamente a partir da década de 1980), a proeminência de agências financeiras internacionais, como o FMI e o Banco Mundial, e a globalização da economia..$^{52}$

Segundo Jose Luis Bolzan de Morais e Maiquel Ângelo Dezordi Wermuth ${ }^{53}$, "com a passagem de um modelo de sociedade amparada pelo Estado Social solidário à uma sociedade de risco securitário, o medo e a insegurança tornam-se companhia indissociáveis do indivíduo" posto que o contraponto das políticas do Welfare State é próprio processo de globalização econômica. O consumo é a ferramenta que pauta a inclusão e a exclusão dos indivíduos, dado que as desigualdades globais acabam por criar dois grandes contingentes: "os incluídos em uma economia globalizada e flexibilizada, por um lado, e os excluídos, carentes de identidade como consequência de sua falta de competência ou de sua impossibilidade para alcançar os mercados de consumo, por outro." ${ }^{54}$

Com a globalização da economia e a emergência do direito transnacional emerge um novo pluralismo jurídico, que pode ser analisado enquanto causa

\footnotetext{
${ }^{51}$ SANTOS, Boaventura de Souza; MARQUES, Maria Manuel Leitão; PEDROSO, João. op. cit., s.a., p. 5.

${ }^{52}$ Idem. p. 5.

${ }^{53}$ BOLZAN DE MORAIS, Jose Luis; WERMUTH, Maiquel Ângelo Dezordi. A Crise do Welfare State e a Hipertrofia do Estado Penal. Sequiência, Florianópolis, v. 34, p. 161-186, 2013, p. 3.

${ }^{54}$ Idem. p. 6.
} 
e consequência da erosão da soberania do Estado nacional que ocorre durante a crise do Estado-providência. Essa erosão dá azo a um forte protagonismo do Poder Judiciário na garantia do controle de legalidade ${ }^{55}$. O surgimento de litígios altamente complexos em razão do surgimento das normas pragmáticas, contratos-programas, cláusulas gerais e afins, contribuiu para o fortalecimento do protagonismo em questão. Desse modo, "a impreparação dos magistrados, combinada com a sua tendência a se refugiarem nas rotinas e no produtivismo quantitativo, fez com que a oferta judiciária fosse nesses litígios altamente deficiente, o que de alguma maneira contribuiu para a erosão da legitimidade dos tribunais" ${ }^{56}$.

Em paralelo, agravam-se as desigualdades sociais. O período também denota uma crise na representação política na figura da corrupção que tanto se alastra nas sociedades democráticas. Com isso, "o afrouxamento das referências éticas no exercício do poder político, combinado com as deficiências do controle do poder por parte dos cidadãos", permite "que essa promiscuidade redundasse num aumento dramático da corrupção." 57

Ademais, o alastramento e a massificação da litigiosidade gera uma espécie de rotina deficitária nos processos. No que tange ao âmbito penal, a criminalidade produz formas, estereótipos, no controle social. Corrobora-se essa tese, que é apresentada pelos autores supracitados, pela ingerência e percepção da criação de perfis dos delinquentes, daqueles que são "criminosos mais recorrentes" e demais fatores criminógenos. Importante ressaltar que, no caso em questão (encarceramento feminino no Brasil), segundo os dados do Conselho Nacional de Justiça:

A população carcerária feminina subiu de 5.601 para 37.380 detentas entre 2000 e 2014 , um crescimento de $567 \%$ em 15 anos. A maioria dos casos é por tráfico de drogas, motivo de $68 \%$ das prisões. Os dados integram o Infopen Mulheres, levantamento nacional de informações penitenciárias do Ministério da Justiça, que, pela primeira vez, aprofunda a análise com o recorte de gênero. ${ }^{58}$

\footnotetext{
${ }_{55}$ SANTOS, Boaventura de Souza; MARQUES, Maria Manuel Leitão; PEDROSO, João. op. cit., s.a.

${ }^{56}$ SANTOS, Boaventura de Souza; MARQUES, Maria Manuel Leitão; PEDROSO, João. op. cit., s.a. p. 6.

${ }^{57}$ Idem. p. 6.

${ }^{58}$ CONSELHO NACIONAL DA JUSTIÇA. População carcerária feminina aumentou 567\% em 15 anos no Brasil. 2015. Disponível em: http://www.cnj.jus.br/noticias/cnj/80853-populacao-carceraria-feminina-aumentou-567em-15-anos-no-brasil. Acesso em: 31 jul. 2018.
} 
No que tange ao perfil das mulheres encarceradas, o Conselho Nacional de Justiça aponta que aproximadamente $30 \%$ das presas no Brasil ainda aguardam julgamento. Por outro lado, os dados apontam que $68 \%$ das mulheres encarceradas no país são negras, sendo que em Estados como o Acre, por exemplo, 100\% das detentas eram negras em junho de 2014. Outros Estados apresentam percentuais extremamente altos de mulheres negras encarceradas: o Ceará apresenta percentual de $94 \%$, seguido da Bahia, com 92\%. Em relação à faixa etária, aproximadamente $50 \%$ das mulheres encarceradas têm entre 18 e 29 anos, e 18\% possuem idade entre 30 e 34 anos, ou seja, a população feminina encarcerada é majoritariamente jovem. No que diz respeito à escolaridade, apenas $11 \%$ das mulheres presas concluíram o ensino médio, sendo que metade das detentas possui o ensino fundamental incompleto e $4 \%$ são analfabetas. O número de concluintes do ensino superior ficou abaixo de $1 \% .^{59}$

Tais dadosforamapresentados no julgamentodoHCem pauta, conjuntamente com demais estatísticas referentes às condições dos presídios femininos e mistos. Essas estatísticas denotam uma grave deficiência do protagonismo do Estado esse sim, obrigatório, conforme os preceitos garantistas da atual Constituição -, que ainda contribui para a perpetuação de uma violência silenciosa por parte da sociedade e demais violências institucionalizadas.

A partir dessa análise, é possível provocar a reflexão de como a impetração do HC sob análise teve sucesso a partir de outros meios, diversos da lei, e a desmistificação da segurança jurídica como resultado único/último da tradição exegética. Para tanto, convém salientar que, como referido no tópico anterior, a PGU defende em seu parecer que o art. $5^{\circ}$, inciso LXVIII, da Constituição Federal confere uma proteção direta e imediata da liberdade de locomoção, e manifestou-se contra a concessão da ordem, uma vez que ela poderia se converter em súmula vinculante ou instrumento de política pública criminal. É a partir desse pronunciamento que se inserem as discussões a seguir.

Lenio Streck, ferrenho opositor ao protagonismo judicial, indaga que o maior perigo das súmulas vinculantes é a criação de premissas ou categorias próprias para a elaboração de deduções/subsunções. Constitui-se um paradoxo: "os juízes podem contrariar leis; se o fizerem, caberá recurso. O que os juízes não podem fazer é ousar contrariar súmulas (isto é o que diz a Lei 12.276). Ou seja, em terrae brasilis a lei 
não vincula; a súmula, sim, mesmo que ela seja contrária à lei e à Constituição!"º Para o autor, diante do perigo da perda da autonomia do direito, para não serem produzidas decisões ativistas, deve-se utilizar da hermenêutica que "proporciona um novo olhar sobre a interpretação e as condições sob as quais ocorre o processo compreensivo" ${ }^{61}$, por meio de um giro linguístico-ontológico, fundado na filosofia do conhecimento.

André Leonardo Copetti Santos e Doglas César Lucas salientam que há limites do protagonismo do Judiciário - quando é aceitável/justificável ou não, pelo ponto de vista da democracia constitucional. Os autores encontram a resposta no âmbito da teoria da justiça, envolvidas as categorias de reconhecimento e distribuição: "entendemos que o protagonismo judicial, ou sua versão mais radical - o ativismo - pode ser justificável quando o conteúdo das decisões seja de reconhecimento de identidades." ${ }^{\prime 2}$

Os autores citam as teorias sobre reconhecimento e redistribuição de Honneth e Fraser para melhor compreensão do tema. Para a última, o reconhecimento é uma questão de estatuto social que requer o reconhecimento de um "estatuto individual de seus membros como parceiros de pleno direito na interação social." Honneth, por seu turno, considera que o reconhecimento é a categoria central, pois considera os conflitos sociais constitutivos de intersubjetividades e dos próprios sujeitos. Esse conflito caracteriza-se como uma luta moral na qual os sujeitos lutam por reconhecimento recíproco de suas identidades, gerando uma pressão social que estabelece garantias de liberdade. Entretanto, existe um ponto de convergência entre Fraser e Honneth: "apesar das diferenças internas, ambos acreditam que o objetivo da justiça social deve ser entendido como a criação de relações sociais que permitam aos sujeitos serem incluídos como membros plenos de uma comunidade política." ${ }^{64}$

A questão que os autores propõem reside exatamente no tema dos limites da decisão judicial. Pontualmente, nos casos em que se exige grande quantidade de

\footnotetext{
${ }^{60}$ STRECK, Lenio Luiz. Hermenêutica, Constituição e autonomia do Direito. In.: Revista de Estudos Constitucionais, Hermenêutica e Teoria do Direito (RECHTD). Unisinos, I (I), p. 65-77, jan./jun. 2009, p. 74.

${ }^{61}$ STRECK, Lenio Luiz. op. cit., 2009, p. 66.

${ }^{62}$ LUCAS, Doglas Cesar; SANTOS, André Leonardo Copetti. Crítica ao protagonismo do poder judiciário. O ativismo judicial entre reconhecimento e redistribuição. Revista Direito e Justiça: reflexões sociojurídicas, Santo Ângelo, ano 18, n. 29, p. 197-230, nov. 2017. Disponível em: http://srvapp2s.urisan.tche.br/seer/index. php/direito_e_justica/article/view/2375/1076. Acesso em: 31 jul. 2018, p. 203.

${ }_{63}^{6}$ LUCAS, Doglas Cesar; SANTOS, André Leonardo Copetti. op. cit., 2017, p. 210.

${ }^{64}$ Idem. p. 214.
} 
dinheiro para sua efetivação, não se pode haver margem de protagonismo, posto que, assim, são comprometidos direitos de outros cidadãos. Ainda, tal atitude desrespeitaria a lei orçamentaria aprovada pelo Poder Legislativo. Um ótimo exemplo desse caso é a judicialização da saúde no Brasil. De outra banda, "questões que envolvem gênero, raça, cor, religião, idade, imigração, refugiados, nacionalidade etc., quando não interfiram diretamente no direito de terceiro e não onerem de modo não planejado os cofres públicos, devem ser enfrentadas pelo Poder Judiciário"65, sempre visando aos processos de reconhecimento. Logo, neste último caso, tratamse de decisões justificáveis. A título de exemplo pode-se mencionar a decisão contida na ADIn $n^{\circ} 4277$ e na ADPF $n^{\circ} 132$, que concedeu a permissão da união civil entre pessoas do mesmo sexo. Nesse sentido,

o que é preciso destacar, em suma, é que decisões judiciais, ainda que recheadas de protagonismo ativista, são aceitáveis e legítimas na medida em que consolidem situações sociais de reconhecimento e ampliação de espaços de liberdade, sem que disso decorra oneração para os demais poderes públicos ou até mesmo para a sociedade civil. Em sentido contrário, decisões com cunho ativista que restrinjam espaços de liberdade já reconhecidos constitucionalmente e importem em dispêndios econômicos a outras partes que não o Poder Judiciário, devem ser evitadas e até mesmo rechaçadas, porque comprometem a dinâmica das escolhas que é de natureza eminentemente política. $^{66}$

O ministro Gilmar Mendes, em seu voto, defendeu a admissibilidade do remédio constitucional para pleito coletivo enfatizando que não haveria óbices legais para tal. Referiu que a concessão poderia propiciar uma atuação mais célere do STF, cujo acervo processual se mostra sobrecarregado. Reiterou a importância do art. 227 da Carta Magna, e entendeu que a decisão foi acertada. Diante de todo o exposto, resta o seguinte questionamento: se apenas a Suprema Corte, como já mencionado pelo ministro Ricardo Lewandowski, na ADPF 347 MG/DF, é capaz de superar os bloqueios políticos e institucionais que impedem o avanço de soluções progressistas, como a sua atuação pode ser eficaz, em setores específicos, quando ainda é refém de outros poderes?

\footnotetext{
${ }^{65}$ Ibidem. p. 220.

${ }^{66}$ LUCAS, Doglas Cesar; SANTOS, André Leonardo Copetti. op. cit., 2017, p. 228.
} 


\section{CONSIDERAÇÕES FINAIS}

O país não consegue atender as diversas demandas decorrentes das especificidades da condição das mulheres gestantes, puérperas e mães encarceradas, pacientes do HC objeto do presente estudo. Imputar-lhes pena mais gravosa por falta de estrutura a que compete ao Estado tutelar, constitui forte violação de direitos humanos e fundamentais, e por si só, já justifica e impele a Corte Constitucional do país adotar uma postura protagonista, pois é o direito de punir que deve ser mitigado nessas questões e não a liberdade individual.

O cumprimento de pena concomitante entre mãe e filhoé via de consequência diante das atuais práticas de encarceramento. A Constituição Federal alude a uma obrigação de reparar o dano por parte do Estado, mas como se revertem os danos sofridos pela mãe e pela criança? O reparo econômico pode se tornar muito mais oneroso ao Estado do que o investimento propriamente dito na estrutura já prevista na Lei de Execuções Penais. Não obstante, tal reparo pode ser insuficiente diante dos prejuízos psicológicos, por exemplo.

É nessa senda que o direito internacional exibe sua importância. Apesar de não existir legalmente um instrumento processual cabível para impetração do HC multitudinário no Brasil, foi por meio de importantes teses, organizações e declarações internacionais que foi possível a concessão da ordem do writ em questão. Ainda que o direito processual coletivo no Brasil seja incipiente, a decisão mostrou-se pioneira para a consideração desse novo instituto, posto que o direito não consegue prever todas as necessidades fáticas do contexto em que se insere, estando sempre apto a transformações.

Parece pouco prudente permitir que haja violações de direitos humanos e fundamentais de forma deliberada por ausência de instrumento processual cabível. No caso em tela, foi utilizado como critério de admissibilidade para a modalidade coletiva do habeas corpus pela analogia - e o direito deve sempre que possível utilizar desse recurso na ausência de demais recursos - aos institutos do mandado de injunção e segurança coletivos. Ainda que importe certo grau de protagonismo, a acertada decisão pautou-se em direitos que reiteram a importância desses na constante luta para a concretização da democracia constitucional. 


\section{REFERÊNCIAS}

ARMELIN, Bruna Dal Fiume. Filhos do cárcere: estudo sobre as mães que vivem com seus filhos em regime fechado. Revista da Graduação, v. 3, n. 2, 2010. Disponível em: http://revistaseletronicas.pucrs.br/ojs/index.php/graduacao/article/ viewFile/7901/5586. Acesso em: 27 ago. 2018.

AUTRAN, Manoel Godofredo d'Alencastro. Do Habeas Corpus e seo recurso ou compilação das disposições legaes, e decisões do Governo a respeito, em exposição simples e methodica, seguida de um formulário do respectivo processo, e de um índice alphabetico. Rio de Janeiro: Garnier, 1879. Disponível em: http://www.stf.jus.br/bibliotecadigital/OR/40968/pdf/40968.pdf. Acesso em: 19 mar. 2018.

BARBOSA, Rui. República: Teoria e Prática - Textos doutrinários sobre direitos humanos e políticos consagrados na Primeira Constituição Republicana. Petrópolis: Vozes, 1978.

BOLZAN DE MORAIS, Jose Luis; WERMUTH, Maiquel Ângelo Dezordi. A Crise do Welfare State e a Hipertrofia do Estado Penal. Seqüência, Florianópolis, v. 34, p. 161-186, 2013.

BRAGA, Ana Gabriela Mendes. Entre a soberania da lei e o chão da prisão: a maternidade encarcerada. Revista Direito GV, São Paulo, v. 11, n. 2, p. 523-546, jul./ dez. 2015. Disponível em: http://bibliotecadigital.fgv.br/ojs/index.php/revdireitogv/ article/view/58121/56586. Acesso em: 25 ago. 2018.

BRAGA, Ana Gabriela Mendes; ANGOTTI, Bruna. O excesso disciplinar: da hipermaternidade à hipomaternidade no cárcere feminino brasileiro. Revista SUR, v. 12 n. 22, p. 229-239, 2015. Disponível em: https://bdjur.stj.jus.br/jspui/ bitstream/2011/101231/hipermaternidade_hipomaternidade_carcere_braga.pdf. Acesso em: 22 ago. 2018.

BRASIL. Código de Processo Penal, Decreto-Lei $n^{0}$ 3.689. Disponível em: http:// www.planalto.gov.br/ccivil_03/Decreto-Lei/Del3689Compilado.htm Acesso em: 28 jul. 2018.

BRASIL. Constituição (1988). Constituição da Republica Federativa do Brasil. Disponível em: http://www.planalto.gov.br/ccivil_03/constituicao/ 
constituicaocompilado.htm. Acesso em: 28 jul. 2018.

BRASIL. Superior Tribunal de Justiça. Habeas Corpus no 142.513 , Espírito Santo, 2010. Disponível em: https://stj.jusbrasil.com.br/jurisprudencia/9217220/habeascorpus-hc-142513-es-2009-0141063-4/inteiro-teor-14297462? ref=juris-tabs. Acesso em: 16 set. 2018.

BRASIL. Superior Tribunal de Justiça. Habeas Corpus no 207.720 São Paulo, 2012. Disponível em: https://stj.jusbrasil.com.br/jurisprudencia/21270485/habeas-corpushc-207720-sp-2011-0119686-3-stj/inteiro-teor-2127048. Acesso em: 16 set. 2018.

BRASIL. Supremo Tribunal Federal. Arguição de Descumprimento de Preceito Fundamental 347/DF, 2015. Disponível em: http://redir.stf.jus.br/paginadorpub/ paginador.jsp?docTP $=$ TP\&docID=10300665. Acesso em: 14 nov. 2018.

BRASIL. Supremo Tribunal Federal. Habeas Corpus $n^{0}$ 143.641 São Paulo, 2018. Disponível em: http://www.stf.jus.br/arquivo/cms/noticiaNoticiaStf/anexo/ HC143641final3pdfVoto.pdf. Acesso em: 25 mar. 2018.

CAPELLETI, Mauro; GARTH, Bryant. Acesso à justiça. Trad. Ellen Gracie Northfleet. Porto Alegre: Sergio Antonio Fabris, 1988.

CONJUR. Adriana Ancelmo consegue HC no Supremo e voltará à prisão domiciliar. São Paulo: Consultor Jurídico - ConJur, 2017. Disponível em: https:// www.conjur.com.br/2017-dez-18/adriana-ancelmo-hc-stf-voltara-prisao-domiciliar. Acesso em: 11 set. 2018.

COMISSÃO INTERAMERICANA DE DIREITOS HUMANOS. Resolução 11/2013. Medida Cautelar no 367-13. Assunto: Pessoas Privadas de Liberdade no "Complexo Penitenciário de Pedrinhas", Brasil. 16 de Dezembro de 2013a. Disponível em: https://www.oas.org/es/cidh/decisiones/pdf/MC367-13-pt.pdf. Acesso em: 09 jan. 2017.

COMISSÃO INTERAMERICANA DE DIREITOS HUMANOS. Resolução 14/2013. Medida Cautelar $\mathrm{n}^{\circ}$ 8-13. Assunto: Pessoas Privadas de Liberdade no "Presídio Central de Porto Alegre", Brasil. 30 de Dezembro de 2013b. Disponível em: http://www.ajuris.org.br/sitenovo/wp-content/uploads/2014/01/Medida-CautelarPres\%C3\%ADdio-Central-30-12-2013.pdf. Acesso em: 09 jan. 2017. 
CONSELHO NACIONAL DE JUSTIÇA. Mutirão Carcerário. Raio X do Sistema Penitenciário Brasileiro. Brasília, 2012. Disponível em: http://www.cnj.jus.br/ sistema-carcerario-e-execucao-penal/pj-mutirao-carcerario. Acesso em: 27 ago. 2018.

CONSELHO NACIONAL DA JUSTIÇA. População carcerária feminina aumentou 567\% em 15 anos no Brasil. Disponível em: http://www.cnj.jus.br/noticias/ cnj/80853-populacao-carceraria-feminina-aumentou-567-em-15-anos-no-brasil Acesso em: 31 jul. 2018.

CORTE INTERAMERICANA DE DIREITOS HUMANOS. Medidas provisórias a respeito do Brasil. Assunto: Complexo Penitenciário de Pedrinhas, 2014. Disponível em: http://www.corteidh.or.cr/docs/medidas/pedrinhas_se_01_por.pdf. Acesso em: 09 jan. 2017.

IG SÃO PAULO. Atendendo a um pedido do Ministério Público Federal, Marcelo Bretas concedeu a advogada que ela saia de casa nos dias de semana; entenda. São Paulo: Último Segundo - iG, 2018. Disponível em: http://ultimosegundo.ig.com.br/ politica/2018-08-28/adriana-ancelmo-tornozeleira-eletronica.htm. Acesso em: 11 set. 2018.

INFOPEN. Levantamento Nacional de Informações Penitenciárias: atualização: junho de 2016. Brasília: Ministério da Justiça e Segurança Pública e Departamento Penitenciário Nacional, 2017. Disponível em: http://depen.gov.br/DEPEN/noticias-1/ noticias/infopen-levantamento-nacional-de-informacoes-penitenciarias-2016/ relatorio_2016_22111.pdf. Acesso em: 13 mar. 2018.

INFOPEN MULHERES. Levantamento Nacional de Informações Penitenciárias: Infopen Mulheres - Junho de 2014. Brasília: Ministério da Justiça e Departamento Penitenciário Nacional, 2014. Disponível em: http://www.justica.gov.br/news/ estudo-traca-perfil-da-populacao-penitenciaria-feminina-no-brasil/relatorio-infopenmulheres.pdf. Acesso em: 13 mar. 2018.

LORDELO, João. O habeas corpus coletivo na jurisprudência do STF: comentários ao julgamento do $\mathrm{HC} \mathrm{n}^{0} 143.641,2018$. Disponível em: https:/www.joaolordelo. com/single-post/2018/03/03/O-habeas-corpus-coletivo-na-jurisprud\%C3\%AAncia-doSTF-coment\%C3\%A1rios-ao-julgamento-do-HC-n\%C2\%BA-143641. Acesso em: 15 mar. 2018.

LUCAS, Doglas Cesar; SANTOS, André Leonardo Copetti. Crítica ao protagonismo 
do poder judiciário. O ativismo judicial entre reconhecimento e redistribuição. Revista Direito e Justiça: reflexões sociojurídicas, Santo Ângelo, ano 18, n. 29, p. 197-230, nov. 2017. Disponível em: http://srvapp2s.urisan.tche.br/seer/index.php/ direito_e_justica/article/view/2375/1076. Acesso em: 31 jul. 2018.

FALCADE, Ires Aparecida (org.). Mulheres invisíveis: por entre muros e grades. Curitiba: JM Editora e Livraria Jurídica, 2016.

MENDES, Gilmar. Maternidade livre, direitos efetivados: O Habeas Corpus coletivo 143.641. Disponível em: https://www.conjur.com.br/2018-abr-07/observatorioconstitucional-maternidade-livre-direitos-efetivados-hc-coletivo-143641. Acesso em: 31 jul. 2018.

PRADO, Geraldo. Parecer: Habeas Corpus Coletivo impetrado em favor dos "flanelinhas". Disponível em: http://emporiododireito.com.br/tag/habeas-corpuscoletivo/. Acesso em: 08 jun. 2017.

REPRODUCTIVE RIGHTS. Caso de Alyne da Silva Pimentel Teixeira ("Alyne") v. Brasil, 2014. Disponível em: https:/www.reproductiverights.org/sites/crr. civicactions.net/files/documents/LAC_Alyne_Factsheet_Portuguese_10\%2024\%20 14_FINAL_0.pdf. Acesso em: 10 set. 2018.

SANTOS, Boaventura de Souza; MARQUES, Maria Manuel Leitão; PEDROSO, João. Os tribunais nas sociedades contemporâneas. Disponível em: http://www.anpocs. org.br/portal/publicacoes/rbcs_00_30/rbcs30_07.htm . Acesso em: 31 jul. 2018.

SARMENTO, Daniel; BORGES, Ademar; Gomes, Camilla. Parecer: O Cabimento do Habeas Corpus Coletivo na Ordem Constitucional Brasileira. 2015. Disponível em: https://www.conjur.com.br/dl/parecer-hc-coletivo.pdf. Acesso em: 13 mar. 2018.

SIMAS, Luciana; VENTURA, Miriam; BAPTISTA, Michelly Ribeiro; LAROUZÉ, Bernard. A jurisprudência brasileira acerca da maternidade na prisão. Revista Direito GV, São Paulo, vol. 11, n. 2, p. 547-572, Jul-Dez 2015. Disponível em: http:/bibliotecadigital. fgv.br/ojs/index.php/revdireitogv/article/view/58122/56587. Acesso em: 25 mar. 2018.

STRECK, Lenio Luiz. Hermenêutica, Constituição e autonomia do Direito. Revista de Estudos Constitucionais, Hermenêutica e Teoria do Direito (RECHTD), v. I, n. I, p. 65-77, jan./jun. 2009. 
STRECK, Lenio Luiz. O pan-principiologismo e o sorriso do lagarto. Conjur. Disponível em: http://www.conjur.com.br/2012-mar-22/senso-incomum-panprincipiologismo-sorriso-lagarto. Acesso em: 11 set. 2018.

WERMUTH, Maiquel Ângelo Dezordi. O "anjo da história" e o expansionismo penal: rumo a um modelo totalitário? Revista Brasileira de Ciências Criminais, v. 140, p. 371-398, fev. 2018.

ZAFFARONI, Eugenio Raúl; BATISTA, Nilo Batista; ALAGIA, Alejandro; SLOKAR, Alejandro. Direito penal brasileiro: primeiro volume - Teoria Geral do Direito Penal. 2. ed. Rio de Janeiro: Revan, 2003.

Recebido em: 17/09/2018

Aceito em: 12/02/2019 